\title{
Sex differences in incidence and mortality of bloodstream infections. Results from the population- based HUNT study in Norway
}

Randi Marie Mohus ${ }^{1,2}$, Lise T. Gustad ${ }^{1,2,3}$, Anne Sofie Furberg ${ }^{4,5}$, Martine Kjølberg Moen ${ }^{1,2}$, Kristin Vardheim Liyanarachi, $^{1,6}$, Assa Askim ${ }^{2}$, Signe E. Assberg ${ }^{1}$, Andrew T. DeWan ${ }^{1,7}$, Tormod Rogne ${ }^{1,7}$, Gunnar Skov Simonsen ${ }^{4,8,9}$, Tom Ivar Lund Nilsen ${ }^{2,10}$, Bjørn Olav Åsvold ${ }^{11,12}$, Jan Kristian Damås $^{1,6,13}$, Erik Solligård ${ }^{1,2}$

1) Gemini Center for Sepsis Research at Institute of Circulation and Medical Imaging, NTNU, Norwegian University of Science and Technology, Trondheim, Norway,

2) Clinic of Anesthesia and Intensive Care, St. Olavs hospital, Trondheim University Hospital, Trondheim, Norway,

3) Nord-Trøndelag Hospital Trust, Levanger, Norway,

4) Department of Microbiology and Infection Control, University Hospital of North Norway, Troms $\varnothing$, Norway,

5) Faculty of Health and Social Sciences, Molde University College, Molde, Norway,

6) Department of Infectious Diseases, St. Olavs hospital, Trondheim University Hospital, Trondheim, Norway,

7) Department of Chronic Disease Epidemiology and Center for Perinatal, Pediatric and Environmental Epidemiology, Yale School of Public Health, New Haven, CT, USA,

8) Research Group for Host-Microbe Interaction, Faculty of Health Sciences, UiT - The Arctic University of

Norway, Troms $\varnothing$, Norway,

9) Norwegian Institute of Public Health, Oslo, Norway,

10) Department of Public Health and Nursing, NTNU, Norwegian University of Science and Technology, Trondheim, Norway,

11) K.G. Jebsen Center for Genetic Epidemiology, Department of Public Health and Nursing, NTNU, Norwegian University of Science and Technology, Trondheim, Norway,

12) Department of Endocrinology, Clinic of Medicine, St. Olavs hospital, Trondheim University Hospital, Trondheim, Norway,

13) Centre of Molecular Inflammation Research, Department of Clinical and Molecular Medicine, NTNU, Norwegian University of Science and Technology, Trondheim, Norway

Corresponding author: Randi Marie Mohus, randi.m.mohus@ntnu.no

\section{Abstract}

Objective To examine the effect of sex on risk of bloodstream infections (BSI) and BSI mortality and to assess to what extent known risk factors for BSI mediate this association in the general population. Participants The prospective, population-based HUNT2 Survey (1995-97) in Norway invited 93,898 inhabitants $\geq 20$ years in the Nord-Trøndelag region, whereof 65,237 (69.5\%) participated. $46.8 \%$ of the participants were men.

Exposures Sex and potential mediators between sex and BSI; health behaviours (smoking, alcohol consumption), education attainment, cardiovascular risk factors (systolic blood pressure, non-HDL cholesterol, body mass index) and previous or current comorbidities.

Main outcome measures Sex differences in risk of first-time BSI, BSI mortality (death within first 30 days after a BSI), BSI caused by the most frequent bacteria, and the impact of known BSI risk factors as mediators. 
medRxiv preprint doi: https://doi.org/10.1101/2021.08.24.21262516; this version posted August 26, 2021. The copyright holder for this preprint

(which was not certified by peer review) is the author/funder, who has granted medRxiv a license to display the preprint in perpetuity.

It is made available under a CC-BY-NC-ND 4.0 International license.

Results We documented a first-time BSI for 1,840 (2.9\%) participants (51.3\% men) during a median follow-up of 14.8 years. Of these, $396(0.6 \%)$ died (56.6\% men). Men had $41 \%$ higher risk of any first-time BSI (95\% confidence interval (CI), 28 to 54\%) than women. An estimated 34\% of the excess risk of BSI in men was mediated by known BSI risk factors. The hazard ratio (HR) with $95 \%$ CI for BSI due to $S$. aureus was 2.09 (1.28 to 2.54), S. pneumoniae 1.36 (1.05 to 1.76), and E. coli 0.97 ( 0.84 to 1.13 ) in men vs women. BSI related mortality was higher in men compared to women with HR 1.87 (1.53 to 2.28).

Conclusions This large population-based study show that men have higher risk of BSI than women. One-third of this effect was mediated by known risk factors for BSI. This raises important questions regarding sex specific approaches to reduce the burden of BSI. 


\section{Introduction}

Bloodstream infection (BSI) is a major global burden (1) and may lead to sepsis which constitutes up to $60 \%$ of the global mortality burden (2-4). The risk of acquiring BSI depends on the bacterial virulence, host characteristics and biological factors (5-9). Epidemiological studies indicate a male predominance in sepsis, nevertheless former studies on sex differences in incidence and mortality of sepsis have given conflicting results $(2,10-14)$. Importantly, disparities in immune function between sexes arise from differences in biological characteristics such as anatomy and hormonal status, medical conditions, health behaviours, lifestyle, and exposure to different pathogens (12,15-17). Most previous studies on sex differences in BSI and sepsis have been performed in small cohorts, mainly from the intensive care unit (ICU), and there are limited population-based studies $(12-14,18,19)$. Studies on severe infections and sepsis tend to adjust for sex in their analyses (20) without focusing on the mechanisms between sex and infection risk (21).

To assess the impact of sex as a risk factor for BSI we used data from the Norwegian HUNT Study linked with hospital-confirmed clinically relevant BSI to estimate the sex specific risk of any firsttime BSI, BSI-related mortality, and first-time BSI caused by the most common infecting bacteria, Staphylococcus (S.) aureus, Streptococcus (S.) pneumoniae and Escherichia (E.) coli. Further, we aimed to investigate the potential mediating effect of health behaviours, education attainment, cardiovascular risk factors and comorbidities on the associations between sex and BSI.

\section{Methods}

\section{Study population}

The HUNT Study is a large-scale population-based health study conducted in mid-Norway and consists of four consecutive surveys inviting the total adult population approximately every $10^{\text {th }}$ year. The second survey (HUNT2, 1995-97) invited all adult inhabitants $\geq 20$ years ( $n=93,898)$ to a clinical examination, non-fasting blood sampling and a comprehensive self-report of health-related topics. Of these, 65,237 (69\%) chose to participate. The HUNT study database is regularly updated with information on date of migration and death from the National Registry. More details on the HUNT study are published elsewhere (22). For the purpose of the present study, we excluded $47(0.07 \%)$ participants who had a prior positive blood culture and 1,150 (1.8\%) who migrated or died before start of follow-up. A total of 64,040 participants were eligible for analyses (Supplemental Figure 1 Flowchart).

\section{Measures}

The exposure is sex as registered in the National Registry. The two main outcomes were first-time BSI and BSI related mortality. All BSIs were confirmed at the microbiology laboratories at Levanger, Namsos or at St. Olavs hospitals. The participants were followed-up for incident BSI by a linkage to the Nord-Trøndelag Hospital Trust (HNT HF) sepsis registry $\boldsymbol{u}$ sing the personal identification number of Norwegian citizens (23). We defined BSI mortality as death occurring within 30 days after detection of any BSI. In secondary analyses we assessed first-time BSI caused by the most common bacteria E. coli, S. aureus and S. pneumonia. Blood cultures solely with microorganisms associated with skin contamination such as coagulase negative Staphylococcus species, Corynebacterium species and Cutibacterium species were not considered as BSI (24).

Mediators are variables that are causally located between exposure and outcome variables, and that partly explain the effect of exposure on outcome (25). We used three distinct sets of mediators measured at inclusion; 1) health behaviours (smoking and alcohol use) and educational attainment; 2) cardiovascular risk factors (body mass index $\left(\mathrm{BMI}, \mathrm{kg} / \mathrm{m}^{2}\right)$, systolic blood pressure $(\mathrm{mmHg})$ and nonhigh-density lipoprotein cholesterol (non-HDL, mmol/L); 3) comorbidities defined by self-report of cardiovascular disease (history of myocardial infarction, angina pectoris, and/or stroke), diabetes, cancer history, lung disease (asthma or chronic obstructive pulmonary disease) and standardised measurements of kidney disease (estimated glomerular filtration rate (eGFR) $<60 \mathrm{ml} / \mathrm{min} / 1.73 \mathrm{~m}^{2}$ ) 
(22). The three sets of mediators reflect known risk factors for BSI. Details about the measurements and categorisation of mediators are included in the supplemental material.

\section{Statistical analyses}

We used Cox proportional hazard regression analysis to estimate the hazard ratios (HRs) with 95\% confidence intervals (CIs) of a first-time BSI and BSI mortality in men compared to women. Attained age was used as the time scale. Start of follow-up was defined by the availability of data in the sepsis registry. For residents belonging to Levanger hospital from 1 January 1995, and for residents belonging to Namsos hospital from 1 September 1999. Patients referred to St. Olavs hospital, the tertiary referral centre, BSI information was included depending on their primary hospital. Participants contributed person-years from inclusion date in HUNT2 except for participants having Namsos as their primary hospital, they entered the HNT HF sepsis registry from 1 September 1999. Data from all hospitals were available through 2011 (23).

In the analysis of BSI risk, participants were followed until their first BSI, for BSI-mortality participants were followed until death within 30 days of any BSI episode, and for both analyses participants were followed until migration out of Nord-Trøndelag, death of all causes or end of follow-up set to 31 December 2011, whichever occurred first. The proportional hazards assumption was examined by visual inspection of log-log plots and tests of Schoenfeld residuals. Using Stata stcompadj, we estimated cumulative incidence and mortality from start of follow-up to first-time BSI and BSI mortality, accounting for death by all causes as a competing risk.

In secondary analyses we estimated HRs and cumulative incidence of first-time BSI caused by the most common infecting bacteria; E. coli, S. aureus and S. pneumoniae using Cox regression and cumulative incidence. To address whether menopause affects women's risk of BSI we conducted a sensitivity analysis stratified by age below and above 50 years.

The proportion of excess risk of BSI in men mediated by known BSI risk factors was estimated using an inverse odds weighting $(I O W)$ procedure $(26,27)$. IOW is a counterfactual method that enables a decomposition of the total effect of the exposure (sex) on the outcome (first-time BSI) into a natural direct effect $(N D E)$ from exposure on outcome, and a natural indirect effect (NIE) through multiple mediators jointly fitted in the model $(25,26)$. The method is robust to unmeasured common causes of the mediators (25).

The inverse odds weights were obtained by regressing the exposure (sex) on all mediators of interest with age as a covariate. In our analysis, the total effect is best interpreted as the total association between exposure (sex) and outcome (first-time BSI), the natural indirect effect is the proportion of excess BSI risk in men mediated by conventional BSI risk factors, whereas the natural direct effect is the proportion of excess BSI risk in men not associated with these factors. The proportion mediated is the percent of the total association that is mediated through the conventional risk factors. A graphic description of the mediation analyses is given in Figure 1. We did not estimate the NIE of individual mediators separately as it may not be appropriate when the mediators affect each other or when single mediator-outcome confounders may be affected by exposure (25). Instead, we estimated the NIE with a sequential mediation approach using three models. This approach assumes that the cardiovascular risk factors and further the comorbidities can be causal descendants of the health behaviours and educational attainment $(25,28)$. In model 1 , we assessed health behaviours and education; in model 2 , we added BMI, systolic blood pressure and non-HDL cholesterol; and in model 3, comorbidities were included to the complete set of mediators. The sequential approach further implies that model 3 reflects the best interpretation of the mediation analyses as all mediators and age are included (25).

We performed bootstrapping based on 1,000 replications to derive percentile-based CIs for all mediation parameters (28). We present the NDE and NIE as HRs with $95 \%$ CIs. The proportion mediated on the log scale was calculated using the formula $\left(\operatorname{lnHR}_{\mathrm{NIE}} / \operatorname{lnHR}_{\mathrm{TOTAL}}\right)(26)$. All statistical analyses were performed using Stata version 16.0. A detailed description of the steps in the IOW analyses is included in supplemental material.

\section{Ethics}


The study was approved by the Regional Committee for Medical and Health Research Ethics of Central Norway (REK no 2012/153 and REK no 94135), and by the HUNT data access committee. Participation in HUNT2 was voluntary, and participants signed a written consent to data collection and linking their data to other registers.

\section{Results}

\section{Population characteristics}

Among 64,040 participants, of whom 46.8\% were men, 1,840 (2.9\%) experienced a BSI and 396 $(0.6 \%)$ died within 30 days after an episode of BSI. The median age at inclusion was similar for both sexes. 51.3\% of first-time BSI cases were men, and 56.6\% of BSI-related deaths occurred in men (Table 1). Both men and women who experienced a BSI were older (median age at inclusion 67.4 and 68.0 respectively), and they had a higher comorbidity burden than participants who did not have a BSI during follow-up.

\section{Risks of BSI and BSI mortality}

Men were more likely to experience a first-time BSI and to die from a BSI compared to women. After adjustments for age, men had 1.41 (HR, 95\% CI 1.28-1.54) higher risk of first-time BSI, and 1.87 (HR, 95\% CI $1.53-2.28$ ) higher risk of dying from a BSI within 30 days (Table 2). In analyses by the most common infecting bacteria compared to women, men had a 2.09 -fold (HR, 95\% CI 1.28 to 2.54 ) increased risk of BSI caused by $S$. aureus, and 1.36 (HR, 95\% CI 1.05 to 1.76) increased risk of $S$. pneumonia. The corresponding result for E. coli did not show higher risk in men with HR of 0.97 (95\% CI 0.84 to 1.13 ) (Table 3 ).

Figure 2 illustrates the above findings by graphing the age-adjusted cumulative incidence of first-time BSI and cumulative BSI mortality. The cumulative incidence of BSI was higher among men than women after the first five years of follow-up. For BSI mortality the sex difference was apparent after the first 2.5 years of follow-up and during follow-up the sex differences in mortality increases substantially. We present cumulative incidence curves for the three most common infecting bacteria in Figure 3A, B and C. Men had higher incidence of S. aureus, especially after the first 7 years of follow-up, whereas $E$. coli had higher cumulative incidence among women.

The age-stratified analyses at estimated menopause ( $\leq 50$ years) did not reveal any clear sex difference in risk of BSI before menopause. However, the youngest age-group had few episodes of BSI, and few persons died from a BSI (Supplemental Table 1).

\section{Mediation analyses}

In Table 4 we present the total effect, the natural direct and indirect effects of sex on risk of first-time BSI. Compared with women men had an estimated HR of 1.40 (95\% CI 1.24 to 1.55) for first-time BSI. Behavioural risk factors and education mediated $10 \%$ of the total effect (model 1), adding the cardiovascular risk factors mediated $5 \%$ (model 2$)$, whereas the whole set of mediators, including comorbidities, jointly mediated $34 \%$ of the total effect (model 3). The mediation results indicate that male sex is a risk factor for BSI, but also that men with increased burden of conventional BSI risk factors are at particular risk. 
medRxiv preprint doi: https://doi.org/10.1101/2021.08.24.21262516; this version posted August 26, 2021. The copyright holder for this preprint (which was not certified by peer review) is the author/funder, who has granted medRxiv a license to display the preprint in perpetuity.

It is made available under a CC-BY-NC-ND 4.0 International license .

Table 1: Baseline characteristics of the study population at inclusion in HUNT2, $n=64,040$

\begin{tabular}{|c|c|c|}
\hline & Men & Women \\
\hline Total population $\mathrm{n}(\%)$ & $29962(46.8)$ & $34087(53.2)$ \\
\hline First-time BSI n (\%) ${ }^{1}$ & $943(51.3)$ & $897(48.7)$ \\
\hline BSI mortality² $\mathrm{n}(\%)$ & $224(56.6)$ & $172(43.4)$ \\
\hline Age (mean, IQR) & $48.6(36.5-62.9)$ & $48.7(36.2-64.2)$ \\
\hline $\begin{array}{l}\text { Smoking } \\
\text { Current } \\
\text { Prior } \\
\text { Never }\end{array}$ & $\begin{array}{c}8334 \\
9422 \\
10668\end{array}$ & $\begin{array}{c}9726 \\
6516 \\
15230\end{array}$ \\
\hline $\begin{array}{l}\text { Alcohol use } \\
<1 \text { unit/ } 2 \text { weeks } \\
1-7 \text { units/ } 2 \text { weeks } \\
814 \text { units/ } 2 \text { weeks } \\
\geq 15 \text { units/ } 2 \text { weeks }\end{array}$ & $\begin{array}{l}8448 \\
14258 \\
4602 \\
1643\end{array}$ & $\begin{array}{c}16069 \\
14484 \\
1861 \\
272\end{array}$ \\
\hline $\begin{array}{l}\text { Education } \\
<10 \text { years } \\
10-12 \text { years } \\
>12 \text { years }\end{array}$ & $\begin{array}{c}20625 \\
2302 \\
5650\end{array}$ & $\begin{array}{c}22259 \\
3436 \\
6412\end{array}$ \\
\hline $\begin{array}{l}\text { BMI }\left(\mathrm{kg} / \mathrm{m}^{2}\right) \\
<18.5 \\
18.5-24.9 \\
25-29.9 \\
30-34.9 \\
35-39.9 \\
\geq 40\end{array}$ & $\begin{array}{c}118 \\
10498 \\
14757 \\
3674 \\
496 \\
74\end{array}$ & $\begin{array}{c}349 \\
14736 \\
12345 \\
4640 \\
1236 \\
344\end{array}$ \\
\hline $\begin{array}{l}\text { Systolic blood pressure }(\mathrm{mmHg}) \\
\text { median (IQR) }\end{array}$ & $\begin{array}{c}137 \\
(127-150)\end{array}$ & $\begin{array}{c}131 \\
(118-149)\end{array}$ \\
\hline $\begin{array}{l}\text { Non-HDL cholesterol (mmol/L) } \\
\text { median (IQR) }\end{array}$ & $\begin{array}{c}4.5 \\
(3.7-5.3)\end{array}$ & $\begin{array}{c}4.3 \\
(3.5-5.3)\end{array}$ \\
\hline $\begin{array}{l}\text { Comorbidities } \\
\text { Cardiovascular disease }^{3} \\
\text { Chronic kidney disease } \\
\text { Diabetes } \\
\text { Cancer history } \\
\text { Chronic lung disease }^{4}\end{array}$ & $\begin{array}{c}2918 \\
979 \\
970 \\
878 \\
1183\end{array}$ & $\begin{array}{c}2014 \\
1802 \\
895 \\
1413 \\
1011\end{array}$ \\
\hline
\end{tabular}

$\mathrm{BS}=$ Bloodstream infection, $\mathrm{n}=$ Numbers, $\mid \mathrm{QR}=$ Interquartile range, $\mathrm{BM}=$ Body mass index. $\mathrm{HDL}=$ High-density lipoprotein 1) Percentage of total first-time BSI in both sexes.

2) BSI mortality was defined as all-cause mortality within 30 days after a BSI.

3) History of myocardial infarction, angina pectoris and/or stroke.

4) History of chronic obstructive pulmonary disease or asthma.

Table 2. Associations of sex with risk of bloodstream infection and BSI mortality

\begin{tabular}{|c|c|c|c|c|c|c|c|c|}
\hline & \multicolumn{4}{|c|}{ Risk of first-time BSI adjusted for age ${ }^{1}$} & \multicolumn{4}{|c|}{ BSI mortality ${ }^{2}$ adjusted for age ${ }^{1}$} \\
\hline & $\begin{array}{l}\text { Years at } \\
\text { risk }\end{array}$ & No. BSI & HR & $95 \% \mathrm{Cl}$ & $\begin{array}{l}\text { Years at } \\
\text { risk }\end{array}$ & $\begin{array}{l}\text { No. BSI } \\
\text { deaths }\end{array}$ & HR & $95 \% \mathrm{Cl}$ \\
\hline Women & 436758 & 897 & 1.0 & Reference & 472012 & 172 & 1.0 & Reference \\
\hline Men & 373915 & 943 & 1.41 & $1.28-1.54$ & 404723 & 224 & 1.87 & $1.53-2.28$ \\
\hline
\end{tabular}

BSI: Bloodstream infection HRs = hazard ratios. $95 \% \mathrm{Cl}=95 \%$ confidence intervals. No. $=$ Numbers

1) Cox regression analyses were adjusted with age as the underlying scale.

2) BSI mortality was defined as all-cause mortality within 30 days after a bloodstream infection. 
medRxiv preprint doi: https://doi.org/10.1101/2021.08.24.21262516; this version posted August 26, 2021. The copyright holder for this preprint (which was not certified by peer review) is the author/funder, who has granted medRxiv a license to display the preprint in perpetuity.

It is made available under a CC-BY-NC-ND 4.0 International license.

Table 3. Associations of sex with risk of bloodstream infections caused by the most common bacteria

\begin{tabular}{|c|c|c|c|c|c|c|c|c|c|c|}
\hline & $\begin{array}{l}\text { Years } \\
\text { at risk }\end{array}$ & $\begin{array}{l}\text { No. } \\
\text { BSI }\end{array}$ & f S. a & reus BSI ${ }^{1}$ & $\begin{array}{l}\text { Risk } \\
\text { BSI1 } \\
\text { No. } \\
\text { BSI }\end{array}$ & of $S$. & $\begin{array}{l}\text { neumoniae } \\
95 \% \mathrm{Cl}\end{array}$ & $\begin{array}{l}\text { Risl } \\
\text { No. } \\
\text { BSI }\end{array}$ & of $E$. & oliBSI1 \\
\hline Women & 436758 & 83 & 1.0 & Reference & 113 & 1.0 & Reference & 399 & 1.0 & Reference \\
\hline Men & 373915 & 129 & 2.09 & $1.28-2.54$ & 119 & 1.36 & $1.05-1.76$ & 285 & 0.97 & $0.84-1.13$ \\
\hline
\end{tabular}

$\mathrm{BSI}$ : Bloodstream infection HRs = hazard ratios. $95 \% \mathrm{Cl}=95 \%$ confidence intervals. No. $=$ Numbers

1) Cox regression analyses were adjusted for age as the underlying scale.

Table 4: Mediation of the associations between sex and BSI by behavioral risk factors, educational attainment, cardiovascular risk factors and comorbidities

\begin{tabular}{|c|c|}
\hline & Risk of first-time BSI \\
\hline Model 1 & \\
\hline $\begin{array}{l}\text { Mediation by behavioural riskfactors }{ }^{1)} \\
\text { and education } \\
\text { Total effect }\end{array}$ & $\begin{array}{l}\text { HRs }(95 \% \mathrm{Cla})^{\mathrm{b}} \\
1.40(1.24-1.55)\end{array}$ \\
\hline Natural direct effect (NDE) & $1.36(1.18-1.57)$ \\
\hline Natural indirect effect (NIE) & $1.04(0.97-1.07)$ \\
\hline Proportion mediated & $10 \%$ \\
\hline Model 2 & \\
\hline $\begin{array}{l}\text { Mediation by behavioural risk factors'1), } \\
\text { education, and cardiovascular risk } \\
\text { factors') }\end{array}$ & HRs $(95 \% \mathrm{Cla})^{b}$ \\
\hline Total effect & $1.40(1.24-1.55)$ \\
\hline Natural direct effect (NDE) & $1.38(1.19-1.58)$ \\
\hline Natural indirect effect (NIE) & $1.02(0.92-1.07)$ \\
\hline Proportion mediated ${ }^{c}$ & $5 \%$ \\
\hline Model 3 & \\
\hline $\begin{array}{l}\text { Mediation by behavioural risk factors }{ }^{11} \text {, } \\
\text { education, cardiovascular risk } \\
\text { factors' }^{21} \text { and comorbidity risk factors }{ }^{3)}\end{array}$ & HRs $\left(95 \% \mathrm{Cla}^{\mathrm{a}}\right)^{\mathrm{b}}$ \\
\hline Total effect & $1.40(1.24-1.55)$ \\
\hline Natural direct effect (NDE) & $1.25(1.05-1.47)$ \\
\hline Natural indirect effect (NIE) & $1.12(1.02-1.17)$ \\
\hline Proportion mediated ${ }^{c}$ & $34 \%$ \\
\hline
\end{tabular}

BSI: Bloodstream infection HRs $=$ hazard ratios. $95 \% \mathrm{Cl}=95 \%$ confidence intervals.

1) Smoking, alcohol use and educational attainment at baseline.

2) Systolic blood pressure, non-high-density lipoprotein cholesterol and Body Mass Index.

3) Cardiovascular disease, chronic kidney disease, diabetes, history of cancer, or chronic lung disease.

a) Percentile-based bootstrap Cls are reported.

b) Estimates are adjusted for age as a covariate.

c) Proportion mediated: (In HR $\mathrm{R}_{\mathrm{NE}}$ / In HRTOTAL).

\section{Discussion}

In this large Norwegian population-based study with a follow-up of more than 15 years, male sex was associated with 1.41 times higher risk of BSI and 1.87 times higher risk of dying from a BSI. An 
estimated $34 \%$ of the increased risk of BSI in men was mediated by conventional BSI risk factors. We additionally found that men had 2.09 times higher risk of BSI caused by $S$. aureus compared to women. Importantly, our findings indicate that male sex contributes as an individual and important risk factor for BSI. However, they do not refute the impact of baseline burden of health behaviours, education and pre-existing chronic health conditions in sex disparities seen in BSI.

\section{Comparison with other studies}

There are few population-based studies on sex differences in the epidemiology of BSI and to our knowledge, no previous mediation analysis has combined conventional risk factors with validated BSI events to examine this topic. The rich baseline information from HUNT2 including chronic medical conditions, cardiovascular risk factors, health behaviours and education attainment allowed us to investigate how these factors mediated the association between sex and BSI. We used the IOW approach which is known to be robust using multiple mediators en bloc, and allowed us to implement causal mediation analyses in a time-to-event context $(25,26)$. The sequential approach enabled us to examine the portion mediated through health behaviours and education, which accounted for $10 \%$. Adding cardiovascular risk factors the proportion mediated accounted for 5\%, indicating some interactions or common pathways for the mediators (25). The complete model accommodate the assumptions required, and most likely reflects the best modelling of the associations (25). In our analyses the proportion mediated by age and all mediators combined was $34 \%$. Interventions to reduce modifiable risk factors in the population will likely reduce the burden of BSI, particularly in aging men with high burden of known risk factors. This is an important finding that deserves further investigations.

The population-based design ensures that all BSI occurring in residents of a defined geographical area are included, which is an advantage over ICU cohorts (29). Our results are supported by one population-based BSI study including 1,051 patients with positive blood cultures showing that men had higher risk of BSI. In particular they found that BSI incidence increases sharply by age, and men had twice the rate of $S$. aureus BSI (18). Another population-based study from Canada comprising 9,266 patients with BSI admitted to ICU found that male sex is a risk factor for BSI (19). From the same research group, a recent study restricted to persons aged $\geq 65$, found that men were at increased risk compared to females (incidence rate ratio 1.44, 95\% CI 1.32-1.59) and the sex difference was most pronounced in the oldest patients (30). On the other hand, the global burden of disease study found that age-standardised sepsis incidence was higher among women, while sepsis-related mortality was higher among men (2). This study included results from 195 countries and comprised all age groups. They found a substantially higher sepsis incidence in low-income countries, and the pattern of sepsis incidence and mortality varied according to location, which is not directly comparable to our study population.

We identified higher BSI mortality in men which is in line a population-based study of BSI in critically ill adults (31), and a recent study on infection related death in UKBiobank (32). Conversely, some ICU studies report higher sepsis-related mortality in women. A retrospective study with 18,757 adult ICU patients, found higher mortality in women (13). The same pattern was observed in a Swedish study on community acquired sepsis where women had $28 \%$ higher odds of dying (10), and in a smaller ICU cohort from Germany studying 709 adults (11). This conflicting evidence concerning sex differences in mortality is most likely due to the heterogeneity of BSI and sepsis depending on the aetiology and the cohort studied $(29,31)$, but may also be affected by sex differences in immune responses $(15-17,33)$ and differences in treatment $(13,34)$.

The second most common infecting agent in our study was $S$. aureus which was far more common in men. S. aureus is associated with superficial infections of soft tissues with the potential for severe invasive infections and is the most important cause of BSI-associated death $(35,36)$. Previous studies indicate higher probability of nasal colonization in men which is a major risk factor for invasive $S$. aureus infections (37). Other studies show that circulating levels of testosterone and use of hormone contraceptives among females alter nasal colonization indicating that sex hormones affect the immune response to $S$. aureus $(38,39)$. The substantially higher prevalence of $S$. aureus colonization in men is 
of particular interest, and preventive measures like eradication or temporary suppression could lower the risk of invasive infections (40), which is especially important in hospitalized patients.

In a sensitivity analysis we found that the sex differences in BSI risk are evident after predicted age of menopause indicating that alterations in both innate and adaptive immune functions with age may be sex specific. Aging is associated with chronic inflammation and a generally reduced immune function. Women face an abrupt decline during menopause, whereas men have a steady decline from second decade of life (41). As in former studies, our study points out that advancing age is a risk factor for developing and dying from BSI and elderly men are at particular risk $(18,19,30)$.

\section{Strengths and limitations of the study}

Major strengths of our study include its large size, the population-based design, long-term follow-up and linkage to all microbiological records which represent the gold standard to identify BSI (29). Reviews of medical records of patients with S. aureus and S. pneumoniae BSI in this cohort showed that $\sim 98 \%$ met the 2001 sepsis criteria $(35,42)$. Our definition of BSI as a laboratory verified positive blood culture, excluding blood cultures solely with microorganisms associated with skin contamination, ascertains the accuracy of the outcome studied. We were able to study BSI incidence and BSI mortality in a large population without the potential referral bias seen in single institution studies of BSI. The complete ascertainment of all BSI allows for an accurate estimation of incidence and mortality in the population, with the potential of risk factor identification and mediation analyses.

There are some limitations of our study that merit attention. First, we lack information on immunosuppressive medication and use of statins before or at time of infection which are known risk factors for BSI and BSI mortality $(9,43)$. Second, investigating BSI is dependent on clinician's suspicion and decision to submit blood cultures for testing, with the chance of some undetected cases. Further, we cannot rule out if the clinical presentation of infections is different in men and women and that this could result in disproportionate blood culture sampling depending on sex. Third, the mediators are only measured once at inclusion to HUNT2 and could have changed during the 15 years of follow-up. This potential misclassification would most likely be non-differential and lead to underestimation of the mediating effect (44). Another concern is the subjective assessment of some mediators, and dichotomised mediators are more prone to possible mediator misclassification. This could lead to underestimation of the indirect effect and overestimation of the direct effect (45).

Despite these limitations and to the best of our knowledge, we present the first large, epidemiological study elucidating sex differences in BSI. With a non-selected, homogenous population-based study with long follow-up on blood-culture verified BSI with known pathogen, our study contributes to a growing body of evidence that sex influence BSI risk.

\section{Meaning of the study and future research}

This study provides important information for clinicians, researchers and policymakers concerning BSIs. We show that sex disparities in BSI cannot be explained by comorbidity burden, health behaviours and educational level alone. The clinical implications of our findings largely depend on elucidation of the underlying mechanisms behind the observed sex differences.

Sex affects the shape of immune responses which is attributed to genetic, hormonal and environmental factors $(15,16,33)$. The human $\mathrm{X}$-chromosome encodes a number of critical genes involved in the regulation of immune functions (33). It is increasingly clear that sex extensively influences the host immune responses, but this sexual dimorphism is underappreciated, and sex bias is a major challenge in clinical trials $(20,34,46)$. Sex hormones act as important modulators of immune functions and responses; testosterone and progesterone are immunosuppressive, while oestradiol is immunoenhancing (16). Few human studies have investigated sex hormones' effects in sepsis.

Interestingly, in covid-19 where men are more prone to a severe course, the use of antiandrogens in men have shown promising results on severity (47). Furthermore, in a review of health records in post-menopausal women with regular use of oestradiol, the fatality risk of covid-19 is reduced by more than $50 \%$ (48). 
Future perspectives of our results include the need for targeted research on how these sex differences could be addressed to achieve a longer and healthier life for both men and women. Additional work should focus on how genetics and epigenetics as well as sex hormones play a role in the sex disparities seen in infectious diseases. Knowledge of mediating factors together with recognition of sex differences in severe infections are important for public health leaders, researchers and clinicians as it can inform preventive actions and identify individuals especially at risk $(21,49)$.

\section{Conclusion}

In this large population-based cohort, men had an increased risk of BSI and BSI mortality, where $34 \%$ risk of BSI was explained by known risk factors. BSI represents an important global burden of disease, and by establishing the presence of sex differences in BSI our study provides as a catalyst for additional investigations. This will advance our understanding of sex specific host-pathogen interactions and sex hormone's immune actions, and potentially lead to targeted management strategies to prevent BSI and sepsis in both men and women.

\section{Competing interests}

All authors have completed the ICMJE uniform disclosure form at www.icmje.org/coi_disclosure.pdf and declare: no support from any organization for the submitted work; no financial relationships with any organisations that might have an interest in the submitted work in the previous three years; no other relationships or activities that could appear to have influenced the submitted work.

\section{Funding}

This work was supported by a grant from The Liaison Committee for education, research, and innovation in Central Norway.

\section{Acknowledgements}

The Trøndelag Health Study (the HUNT study) is a collaboration of the HUNT research center (Faculty of Medicine and Health Sciences, NTNU, Norwegian University of Science and Technology), Trøndelag County Council, Central Norway Regional Health Authority, and the Norwegian Institute of Public Health.

We sincerely thank Arne Mehl (1948-2021) for his extensive and thorough work with the HNT HF sepsis registry, the microbiology departments of Levanger, Namsos and St. Olav hospitals for providing microbial data, and the Department for Research at Nord-Trøndelag Hospital Trust for assistance with data linkage.

\section{Contribution}

RMM, LG, MKM, KVL, SEÅ, TN, JKD and ES conceived and designed the study. TN, BOÅ, LG, ATD, TR, JKD and ES supervised the study. RMM, BOÅ, $\AA A$ and LG contributed in the acquisition of data for statistical analyses. RMM analyzed the data, prepared tables and figures. RMM, LG, ASF, MKM, KVL, Å, SEÅ, GSS, TR, TN, ATD, BOÅ, ES and JKD interpreted the results and drafted the manuscript. RMM, LG, ASF, MKM, KVL, Å, SEA, ATD, TR, GSS, TN, BO, JKD and ES contributed to the discussions and revised the manuscript critically for important intellectual content. All the authors have read and approved the final version of manuscript and agreed to be accountable for all aspects of the work.

\section{References}

1. Goto M, Al-Hasan MN. (2013) Overall burden of bloodstream infection and nosocomial bloodstream infection in North America and Europe. Clin Microbiol Infect 19(6):501-9. https://doi.org/10.1111/1469-0691.12195

2. Rudd KE, Johnson SC, Agesa KM, Shackelford KA, Tsoi D, Kievlan DR, et al. (2020) Global, regional, and national sepsis incidence and mortality, 1990-2017: analysis for the Global Burden of Disease Study. Lancet 395(10219):200-11. https://doi.org//10.1016/s0140-6736(19)32989-7 
3. Singer M, Deutschman CS, Seymour CW, Shankar-Hari M, Annane D, Bauer M, et al. (2016) The Third International Consensus Definitions for Sepsis and Septic Shock (Sepsis-3). Jama 315(8):801-10. https://doi.org/10.1001/jama.2016.0287

4. Prescott HC, Osterholzer JJ, Langa KM, Angus DC, Iwashyna TJ. (2016) Late mortality after sepsis: propensity matched cohort study. BMJ 353:i2375. https://doi.org/10.1136/bmj.i2375

5. Reddick LE, Alto NM. (2014) Bacteria fighting back: how pathogens target and subvert the host innate immune system. Mol Cell 54(2):321-8. https://doi.org/10.1016/j.molcel.2014.03.010

6. Paulsen J, Askim A, Mohus RM, Mehl A, Dewan A, Solligard E, et al. (2017) Associations of obesity and lifestyle with the risk and mortality of bloodstream infection in a general population: a 15-year follow-up of 64027 individuals in the HUNT Study. Int J Epidemiol 46(5):1573-81. https://doi.org/10.1093/ije/dyx091

7. Mohus RM, Paulsen J, Gustad L, Askim Å, Mehl A, DeWan AT, et al. (2018) Association of iron status with the risk of bloodstream infections: results from the prospective population-based HUNT Study in Norway. Intensive Care Med 44(8):1276-83. https://doi.org/10.1007/s00134-018-5320-8

8. Askim A, Gustad LT, Paulsen J, Reitan SK, Mehl A, Mohus RM, et al. (2018) Anxiety and Depression Symptoms in a General Population and Future Risk of Bloodstream Infection: The HUNT Study. Psychosom Med 80(7):673-9. https://doi.org/10.1097/psy.0000000000000619

9. Tolsma V, Schwebel C, Azoulay E, Darmon M, Souweine B, et al. (2014) Sepsis severe or septic shock: outcome according to immune status and immunodeficiency profile. Chest 146: 1205-1213. https://doi.org/10.1378/chest.13-2618

10. Sunden-Cullberg J, Nilsson A, Inghammar M, (2020) Sex-based differences in ED management of critically ill patients with sepsis: a nationwide cohort study. Intensive Care Medicine 46: 727-736. https://doi.org/10.1007/s00134-019-05910-9

11. Nachtigall I, Tafelski S, Rothbart A, Kaufner L, Schmidt M, Tamarkin A, et al. (2011) Gender-related outcome difference is related to course of sepsis on mixed ICUs: a prospective, observational clinical study. Crit Care 15(3):R151. https://doi.org/10.1186/cc10277

12. Esper AM, Moss M, Lewis CA, Nisbet R, Mannino DM, Martin GS. (2006) The role of infection and comorbidity: Factors that influence disparities in sepsis. Crit Care Med 34(10):2576-82. https://doi.org/10.1097/01.Ccm.0000239114.50519.0e

13. Pietropaoli AP, Glance LG, Oakes D, Fisher SG. (2010) Gender differences in mortality in patients with severe sepsis or septic shock. Gend Med 7(5):422-37. https://doi.org/.1016/j.genm.2010.09.005

14. Adrie C, Azoulay E, Francais A, Clec'h C, Darques L, Schwebel C, et al. (2007) Influence of gender on the outcome of severe sepsis: a reappraisal. Chest 132(6):1786-93. https://doi.org/10.1378/chest.070420

15. Vázquez-Martínez ER, García-Gómez E, Camacho-Arroyo I, González-Pedrajo B. (2018) Sexual dimorphism in bacterial infections. Biol Sex Differ 9(1):27. https://doi.org/10.1186/s13293-018-0187-5

16. Klein SL, Flanagan KL. (2016) Sex differences in immune responses. Nat Rev Immunol 16(10):62638. https://doi.org/10.1038/nri.2016.90

17. vom Steeg LG, Klein SL. (2016) SeXX Matters in Infectious Disease Pathogenesis. PLoS Pathog 12(2):e1005374. https://doi.org/.1371/journal.ppat.1005374

18. Uslan DZ, Crane SJ, Steckelberg JM, Cockerill FR, 3rd, St Sauver JL, Wilson WR, et al. (2007) Ageand sex-associated trends in bloodstream infection: a population-based study in Olmsted County, Minnesota. Arch Intern Med 167(8):834-9. https://doi.org/10.1001/archinte.167.8.834

19. Laupland KB, Gregson DB, Zygun DA, Doig CJ, Mortis G, Church DL. (2004) Severe bloodstream infections: a population-based assessment. Crit Care Med 32(4):992-7. https://doi.org/10.1097/01.ccm.0000119424.31648.1e

20. Shapiro JR, Klein SL, Morgan R. (2021) Stop 'controlling' for sex and gender in global health research. BMJ Glob Health 6(4). https://doi.org//10.1136/bmjgh-2021-005714

21. WHO. Addressing sex and gender in epidemic-prone infectious diseases (2007). Geneva: World Health Organization; https://apps.who.int/iris/handle/10665/43644 accessed 10 August 2021.

22. Krokstad S, Langhammer A, Hveem K, Holmen T, Midthjell K, Stene T, et al. (2012) Cohort Profile: The HUNT Study, Norway. Int J Epidemiol 42(4):968-77. https://doi.org/10.1093/ije/dys095

23. Mehl A, Åsvold BO, Lydersen S, Paulsen J, Solligård E, Damås JK, et al. (2017) Burden of bloodstream infection in an area of Mid-Norway 2002-2013: a prospective population-based observational study. BMC Infect Dis 17(1):205. https://doi.org/10.1186/s12879-017-2291-2

24. Hall KK, Lyman JA. (2006) Updated review of blood culture contamination. Clin Microbiol Rev 19(4):788-802. https://doi.org/10.1128/cmr.00062-05

25. VanderWeele T, Vansteelandt S. (2014) Mediation Analysis with Multiple Mediators. Epidemiol Methods 2(1):95-115. https://doi.org/10.1515/em-2012-0010 
26. Nguyen QC, Osypuk TL, Schmidt NM, Glymour MM, Tchetgen Tchetgen EJ. (2015) Practical guidance for conducting mediation analysis with multiple mediators using inverse odds ratio weighting. Am J Epidemiol 181(5):349-56. https://doi.org/10.1093/aje/kwu278

27. Hossin MZ, Koupil I, Falkstedt D. Early life socioeconomic position and mortality from cardiovascular diseases: an application of causal mediation analysis in the Stockholm Public Health Cohort. BMJ Open. 2019;9(6):e026258. https://doi.org/10.1136/bmjopen-2018-026258

28. Preacher KJ, Hayes AF. (2008) Asymptotic and resampling strategies for assessing and comparing indirect effects in multiple mediator models. Behav Res Methods 40(3):879-91. https://doi.org/10.3758/brm.40.3.879

29. Laupland KB. (2013) Defining the epidemiology of bloodstream infections: the 'gold standard' of population-based assessment. Epidemiol Infect 141(10):2149-57.

https://doi.org/10.1017/s0950268812002725

30. Laupland KB, Pasquill K, Steele L, Parfitt EC. (2021) Burden of bloodstream infection in older persons: a population-based study. BMC Geriatr 21(1):31. https://doi.org/10.1186/s12877-020-01984-z

31. Laupland KB, Davies HD, Church DL, Louie TJ, Dool JS, Zygun DA, et al. (2004) Bloodstream infection-associated sepsis and septic shock in critically ill adults: a population-based study. Infection 32(2):59-64. https://doi.org/10.1007/s15010-004-3064-6

32. Drozd M, Pujades-Rodriguez M, Lillie PJ, Straw S, Morgan AW, Kearney MT, et al. Noncommunicable disease, sociodemographic factors, and risk of death from infection: a UK Biobank observational cohort study. The Lancet Infectious Diseases. 2021;21(8):1184-91. https://doi.org/10.1016/S1473-3099(20)30978-6

33. Libert C, Dejager L, Pinheiro I. (2010) The X chromosome in immune functions: when a chromosome makes the difference. Nat Rev Immunol 10(8):594-604. https://doi.org/10.1038/nri2815

34. Mauvais-Jarvis F, Bairey Merz N, Barnes PJ, Brinton RD, Carrero JJ, DeMeo DL, et al. (2020) Sex and gender: modifiers of health, disease, and medicine. Lancet 396(10250):565-82. https://doi.org/10.1016/s0140-6736(20)31561-0

35. Paulsen J, Mehl A, Askim A, Solligard E, Asvold BO, Damas JK. (2015) Epidemiology and outcome of Staphylococcus aureus bloodstream infection and sepsis in a Norwegian county 1996-2011: an observational study. BMC Infect Dis 15:116. https://doi.org/10.1186/s12879-015-0849-4

36. Laupland KB, Lyytikäinen O, Søgaard M, Kennedy KJ, Knudsen JD, Ostergaard C, et al. (2013) The changing epidemiology of Staphylococcus aureus bloodstream infection: a multinational populationbased surveillance study. Clin Microbiol Infect 19(5):465-71. https://doi.org/10.1111/j.14690691.2012.03903.x

37. Sakr A, Brégeon F, Mège JL, Rolain JM, Blin O. (2018) Staphylococcus aureus Nasal Colonization: An Update on Mechanisms, Epidemiology, Risk Factors, and Subsequent Infections. Front Microbiol 9:2419. https://doi.org/10.3389/fmicb.2018.02419

38. Stensen DB, Småbrekke L, Olsen K, Grimnes G, Nielsen CS, Sollid JUE, et al. (2021) Circulating sexsteroids and Staphylococcus aureus nasal carriage in a general female population. Eur J Endocrinol 184(2):337-46. https://doi.org/10.1530/eje-20-0877

39. Stensen DB, Småbrekke L, Olsen K, Grimnes G, Nielsen CS, Simonsen GS, et al. (2019) Hormonal contraceptive use and Staphylococcus aureus nasal and throat carriage in a Norwegian youth population. PLOS ONE 14(7):e0218511. https://doi.org/10.1371/journal.pone.0218511

40. Liu Z, Norman G, Iheozor-Ejiofor Z, Wong JK, Crosbie EJ, Wilson P. (2017) Nasal decontamination for the prevention of surgical site infection in Staphylococcus aureus carriers. Cochrane Database Syst Rev 5(5):Cd012462. https://doi.org/10.1002/14651858.CD012462.pub2

41. Giefing-Kröll C, Berger P, Lepperdinger G, Grubeck-Loebenstein B. How sex and age affect immune responses, susceptibility to infections, and response to vaccination. Aging Cell. 2015;14(3):309-21. https://doi.org/10.1111/acel.12326

42. Askim A, Mehl A, Paulsen J, DeWan AT, Vestrheim DF, Asvold BO, et al. (2016) Epidemiology and outcome of sepsis in adult patients with Streptococcus pneumoniae infection in a Norwegian county 1993-2011: an observational study. BMC Infect Dis 16:223. https://doi.org/10.1186/s12879-016-15538

43. Mehl A, Harthug S, Lydersen S, Paulsen J, Åsvold BO, Solligård E, et al. (2015) Prior statin use and 90-day mortality in Gram-negative and Gram-positive bloodstream infection: a prospective observational study. Eur J Clin Microbiol Infect Dis 34(3):609-17. https://doi.org/10.1007/s10096-0142269-6

44. Rothman K. LT. Modern Epidemiology. 4th Ed. ed: Lippincott Williams \& Wilkins (LWW); 2020.

45. Richiardi L, Bellocco R, Zugna D, (2013) Mediation analysis in epidemiology: methods, interpretation and bias. Int J Epidemiol 42(5):1511-9. https://doi.org/10.1093/ije/dyt127 
46. Wallach JD, Sullivan PG, Trepanowski JF, Steyerberg EW, Ioannidis JP. Sex based subgroup differences in randomized controlled trials: empirical evidence from Cochrane meta-analyses. Bmj. 2016;355:i5826. https://doi.org/10.1136/bmj.i5826

47. Cadegiani FA, McCoy J, Gustavo Wambier C, Goren A, (2021) Early Antiandrogen Therapy With Dutasteride Reduces Viral Shedding, Inflammatory Responses, and Time-to-Remission in Males With COVID-19: A Randomized, Double-Blind, Placebo-Controlled Interventional Trial (EAT-DUTA AndroCoV Trial - Biochemical). Cureus13(2):e13047. https://doi.org/10.7759/cureus.13047

48. Seeland U, Coluzzi F, Simmaco M, Mura C, Bourne PE, Heiland M, et al. (2020). Evidence for treatment with estradiol for women with SARS-CoV-2 infection. BMC Med 18(1):369. https://doi.org/10.1186/s12916-020-01851-z

49. Evagora-Campbell M, Borkotoky K, Sharma S, Mbuthia M. From routine data collection to policy design: sex and gender both matter in COVID-19. The Lancet. 2021;397(10293):2447-9.

https://doi.org/10.1016/S0140-6736(21)01326-X 
medRxiv preprint doi: https://doi.org/10.1101/2021.08.24.21262516; this version posted August 26, 2021. The copyright holder for this preprint (which was not certified by peer review) is the author/funder, who has granted medRxiv a license to display the preprint in perpetuity.

\section{It is made available under a CC-BY-NC-ND 4.0 International license .}

Figure 1. Mediation analysis

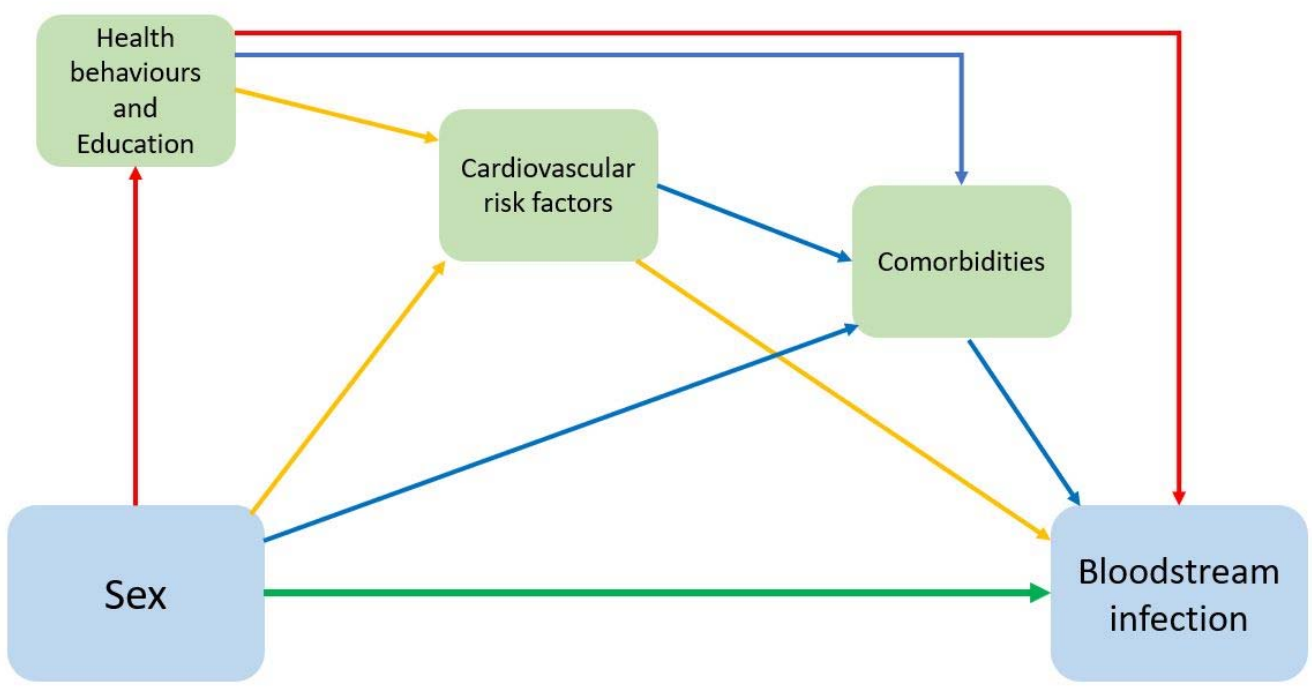

Diagram of the direct and indirect (i.e. mediated) effects of sex on bloodstream infection. The green arrow represents the natural direct effect of the association. Red arrows represent model 1, proportion mediated by health behaviours and education attainment. Yellow arrows represent model 2, proportion mediated jointly by health behaviours, education, and cardiovascular risk factors. Blue arrows represent model 3, proportion mediated jointly by health behaviours, education, cardiovascular risk factors and comorbidities.

Model 1) Smoking, alcohol use and educational attainment at baseline.

Model 2) Systolic blood pressure, non-high-density lipoprotein cholesterol and Body Mass index.

Model 3) Cardiovascular disease, chronic kidney disease, diabetes, history of cancer, and chronic lung disease. 
Figure 2: Sex differences in cumulative incidence and mortality of BSI
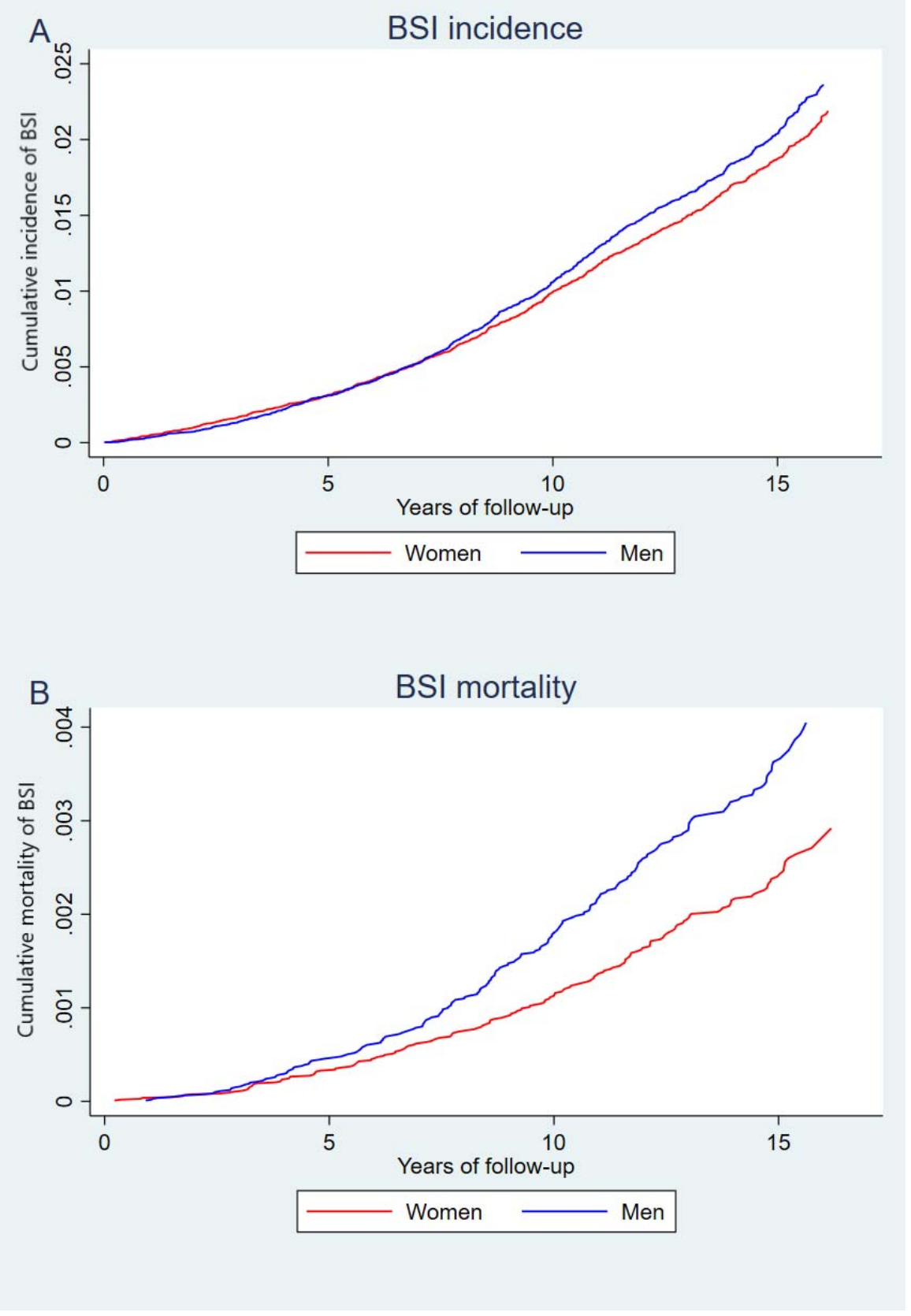

Figure 2: Age-adjusted sex difference in cumulative incidence of BSI (A), and in cumulative mortality (B), estimated for age 49.99 (the mean age of the total population). Note: due to the variation in incidence of different outcomes the scale of the $Y$ axis is not uniform across the panels. 
medRxiv preprint doi: https://doi.org/10.1101/2021.08.24.21262516; this version posted August 26, 2021. The copyright holder for this preprint (which was not certified by peer review) is the author/funder, who has granted medRxiv a license to display the preprint in perpetuity.

It is made available under a CC-BY-NC-ND 4.0 International license .

Figure 3: Sex differences in cumulative incidence of BSI caused by the most common bacteria
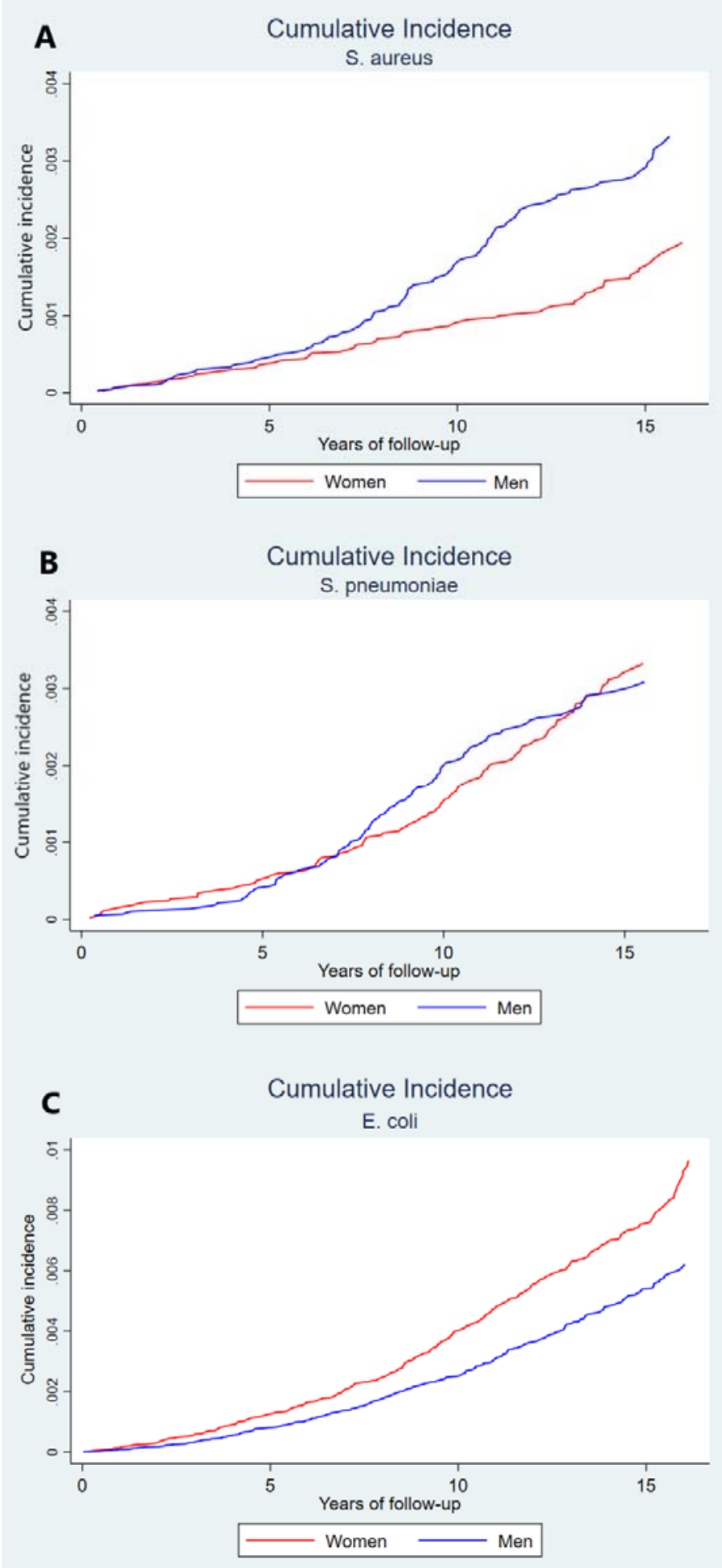

Figure 3: Age-adjusted sex difference in cumulative incidence of $S$. aureus (A), S. pneumoniae (B), and E. coli (C), estimated for age 49.99 (the mean age of the total population). Note: due to the variation in incidence of different bacteria the scale of the $Y$-axis is not uniform across the panels. 